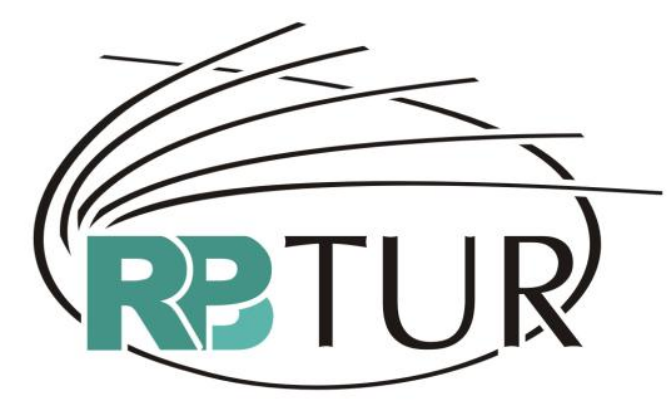

REVISTA BRASILEIRA DE PESQUISA EM TURISMO

\title{
O TURISMO NO CONTEXTO DA SOCIEDADE INFORMACIONAL
}

\author{
TOURISM IN THE INFORMATIONAL SOCIETY CONTEXT
}

\section{EL TURISMO EN EL CONTEXTO DE LA SOCIEDAD INFORMACIONAL}

\author{
Andréa do Nascimento Barbosa Cacho ${ }^{1}$ \\ Francisco Fransualdo de Azevedo ${ }^{2}$
}

\begin{abstract}
Resumo: o presente artigo aborda o turismo no contexto da sociedade informacional, relatando os acontecimentos históricos que antecedem tal sociedade, a primeira e segunda fase da revolução industrial. Descreve o comportamento dessa sociedade e suas relações de trabalho e de lazer. Tem como objetivo analisar a sociedade informacional e o turismo, avaliando as conseqüências das evoluções tecnológicas no setor de viagens e turismo. Além disso, trata de turismo e informação, baseado no uso da internet e suas conseqüências no mercado turístico. Dentre os principais resultados constatados estão: a aceleração no processo de consumo de bens e serviços turísticos mediante 0 uso das novas tecnologias, 0 conseqüente barateamento dos serviços turísticos em virtude da informatização dos processos das empresas e o fim dos intermediários, bem como o aumento do fluxo das viagens mundiais. Trata-se, portanto, de pesquisa bibliográfica em livros e artigos científicos.
\end{abstract}

Palavras-chave: Turismo. Sociedade informacional. Tecnologia da informação.

Abstract: this paper aims to analyze consumer behavior in informational society through a historical approach beginning at the first and second industrial revolutions. Social behavior is described as well as relations between work and leisure time. This paper also describes relationships between society and tourism by analyzing the consequences of technological evolution in travel and tourism. It focuses mainly on

\footnotetext{
${ }^{1}$ Mestranda em Turismo pelo Programa de Pós-Graduação em Turismo da UFRN. Bacharel em Turismo pela mesma instituição. Técnica em Turismo pelo IFRN. Guia de Turismo pelo IFRN. Atua na área de Turismo e Tecnologia da Informação. Email: deiacacho@gmail.com

2 Bacharel em Ciências Econômicas. Licenciado em Geografia. Mestre em Geografia pela Universidade Federal de Sergipe. Doutor em Geografia pela Universidade Federal de Uberlândia, com Estágio Doutoral na Universidade de Barcelona - Espanha, sob tutoria de Horácio Capel. Professor Adjunto I do Departamento de Geografia da Universidade Federal do Rio Grande do Norte. Pesquisador do CNPq. Coordenador de projetos de pesquisa e extensão. Email: ffazevedo@gmail.com
} 
the use of Internet and its consequences in tourist market. The results showed that consumption of tourism goods and services has increased due to the use of new technologies, consequent lowering of prices and reduction of intermediation, as well as to the increasing tourist flows. It was a bibliographical research on books and journals.

Keywords: Tourism. Informational society. Information technology.

Resumen: este artículo aborda el turismo en el contexto de la sociedad informacional, relatando los acontecimientos históricos que preceden a tal sociedad, la primera y la segunda fase de la revolución industrial. Describe el comportamiento de esa sociedad y sus relaciones de trabajo y recreación. Tiene como objetivo analizar la sociedad informacional y el turismo, evaluando las consecuencias de las evoluciones tecnológicas del sector de viajes y turismo. Trata además del turismo y la información enfocando la internet y sus consecuencias en el mercado turístico. Entre los principales resultados constatados están: la aceleración en el proceso de consumo de bienes y servicios turísticos mediante el uso de nuevas tecnologías, la consecuente disminución de los precios de los servicios turísticos gracias a la informatización de los procesos empresariales y el fin de los intermediarios, así como el aumento de la cantidad de viajes a nivel mundial. Se trata de una investigación bibliográfica en libros y artículos científicos

Palabras clave: Turismo. Sociedad informática. Tecnología de la información.

\section{Introdução}

O turismo enquanto atividade socioeconômica vem ganhando destaque por sua expressiva participação no PIB mundial, bem como pela sua capacidade de geração de emprego e renda. Ademais, o que chama mais a atenção dos pesquisadores deste tema e, principalmente, dos economistas são as estimativas de crescimento do setor para as próximas décadas. No entanto, é sabido que este crescimento não significa necessariamente desenvolvimento econômico e social, pois muitas vezes a riqueza gerada no interior desse processo mantém inalteradas as estruturas sociais marcadas muitas vezes por desigualdade e exclusão social.

Mesmo assim, de acordo com Blanke e Chiesa (2009), a importância do setor de viagens e turismo não pode ser subestimada, pois em 2008 os números de desembarques no mundo alcançaram 924 milhões, o que representou aumento de dois por cento em relação ao ano de 2007. Embora na segunda metade de 2008 o setor tenha sofrido uma desaceleração em virtude da crise mundial (crédito) nota-se que sua taxa de crescimento 
continua estável. E dentre uma das razões para isso, destaca-se o aumento do tempo destinado ao lazer, pois diante das evoluções tecnológicas uma parcela da população tem como opção o trabalho intradomiciliar ou a possibilidade de dispor de horas de trabalho mais flexíveis.

Apesar de dos avanços observados sabe-se também que os benefícios gerados não são destinados a todos os trabalhadores, embora influencie a indústria do turismo em virtude de um universo significativo de pessoas se enquadrar no perfil de turista, especialmente aqueles indivíduos que dispõem de dinheiro e tempo para viajar.

Destarte, é evidente que este processo não ocorre de forma homogênea e igualitária espacial e territorialmente, pois como todos os eventos e processos ocorridos no interior da sociedade capitalista, a contradição e a desigualdade sempre marcam o contexto de relações socioespaciais. Dessa forma, nota-se que tais avanços no fenômeno turístico atingem sobretudo os principais espaços indutores, a exemplo dos principais destinos europeus e estadunidenses, que em alguns aspectos coincidem com os principais espaços emissores.

Com a contínua ascensão do turismo a informação torna-se fundamental, uma vez que sem ela o mesmo não funcionaria, muito menos se expandiria. Daí a importância do acesso a informações precisas, confiáveis e relevantes para ajudar o consumidor na tomada de decisão (O'CONNOR, 2001). Ora, todo aquele que viaja necessita do mínimo de informações acerca do local a ser visitado para que assim possa planejar e fazer suas escolhas à medida que aumenta a tendência no sentido de viagens mais independentes. Outro ponto a ser destacado é que o tempo tornou-se uma "economia escassa", fato que torna as férias para muitos consumidores um elevado investimento emocional que não pode ser facilmente substituído, se algo der errado.

Em virtude disso, para Stewart (1998 apud QUEVEDO, 2007, p.17), "nesta nova revolução, o conhecimento é mais importante que os ativos aos quais as empresas se acostumaram". A nova revolução à qual a autora se 
refere é a da informação, a qual vem transformando o mundo e suas relações, sendo sua riqueza maior o conhecimento.

A revolução informacional vem transformando consideravelmente a sociedade global, uma vez que esta exige uma economia baseada na informação. O turismo é, por sua vez, um dos setores que vem sofrendo notórios impactos quanto ao uso da Internet, embora esta não seja o único elemento característico da sociedade informacional, mas um dos principais. Essa tecnologia é um instrumento potencial para a implementação de mudanças na estrutura e nos processos do setor turístico como um todo. 0 setor de viagens aéreas, em particular, experimentou nas duas últimas décadas, mudanças significativas no que se refere aos canais de distribuição dos seus produtos. Em certa medida, isto também vem ocorrendo no setor de hotelaria, pois cada vez os meios de hospedagem aderem a Internet como instrumento importante nos seus negócios. Todas essas mudanças somente se tornaram possíveis graças às tecnologias da informação e comunicação - TIC. (PEASE, ROWE e COOPER, 2007).

Entretanto, é importante considerar que o avanço do meio técnicoinformacional não foge a regra dos processos que ocorrem no âmbito do modo de produção capitalista, haja vista que o sistema informacional também atinge desigual e contraditoriamente os lugares e os espaços regionais. Por conseguinte, apenas uma parte da sociedade usufrui efetivamente dos avanços técnicos e informacionais, bem como daquilo que envolve o processo de turistificação dos espaços.

É notório que o capitalismo contemporâneo é caracterizado por sua expansão voraz e rápida, sempre tentando superar os limites de tempo e espaço. Foi no final do século $X X$ que a economia mundial tornou-se verdadeiramente global, dentre outras razões, graças às tecnologias da informação e comunicação. De fato nem tudo é global na economia, pois a maior parte da produção, empregos e empresas são e continuarão sendo locais e regionais. (CASTELLS, 2000). Além disso, vale salientar que um dos 
componentes essenciais dessa Nova Economia é o networking ou sociedade em rede.

Para o turismo, as tecnologias representam um fator dinâmico e poderoso, sendo capaz de profundas e numerosas transformações no que se refere à distribuição dos serviços turísticos. Nas últimas duas décadas, várias mudanças vêm ocorrendo, afetando muitas vezes o comportamento do profissional, empresário do turismo e, principalmente do consumidor turístico. (OMT, 2003).

Portanto, o presente artigo abordará o turismo no contexto da sociedade informacional, tentando evidenciar o relacionamento e os impactos das tecnologias sobre a atividade turística.

\section{Antecedentes Históricos da Sociedade Informacional}

O turismo ganha força como atividade socioeconômica a partir da Revolução Industrial, sendo esta marcada principalmente pelo surgimento de novas tecnologias que foram responsáveis por transformações significativas no processo de produção. A mecanização dos processos de produção marca uma nova fase na indústria mundial, pois a partir desta houve uma aceleração na produção e, consequentemente, uma acentuada automação das atividades manuais e repetitivas. Vale destacar também outro acontecimento importante: a separação entre o local de trabalho e de residência.

Para alguns historiadores, a Revolução Industrial é dividida em duas fases e a primeira delas teve início no último terço do século XVIII, caracterizando-se por novas tecnologias como: a máquina a vapor e o tear mecânico. (CASTELLS, 2000). A segunda fase dessa revolução, aproximadamente cem anos depois, é marcada por uma série de avanços dentro da indústria química, elétrica, de petróleo e de aço. Destacam-se, também, nesse período outros progressos como: a introdução de navios de aço movidos a vapor, o desenvolvimento do avião, a produção em massa de bens 
de consumo, o sistema de embalagens de alimentos (enlatados), a refrigeração mecânica, outras técnicas de preservação de comida, a invenção do telefone eletromagnético (o início das tecnologias da comunicação) e as ferrovias, que à época serviam exclusivamente para o transporte de cargas. Esta última exerceu papel crucial não só para a indústria, mas para o desenvolvimento do turismo e das comunicações.

Vale salientar que o primeiro período da Revolução Industrial foi marcado por desemprego no campo e migração de trabalhadores rurais empobrecidos para as cidades, em busca de empregos na indústria. A abundância da oferta de mão-de-obra, que incluía crianças e mulheres, teve relação direta com os baixos salários e a degradação das condições de trabalho, haja vista o exército reserva de mão-de-obra que fora criado. Segundo Cormack $(1998$, p.9) "em 1815, a vida para as minorias nunca poderia ter sido melhor, enquanto que para a maioria não poderia ter sido pior".

Como conseqüência dessa situação crescem os movimentos da classe proletariada, através dos sindicatos que passam a reivindicar reduções da jornada de trabalho, tempo livre (folga) e o fim dos abusos como o trabalho infantil "perverso". Diante deste novo quadro e após anos de luta ocorre a instituição do tempo livre, o qual surge também como uma "alternativa" de capturar o tempo ocioso dos trabalhadores. A princípio, século XVIII, as férias para a massa trabalhadora significavam alguns dias de folga não remunerados do trabalho. A idéia de viagem como temos hoje era quase inexistente, especialmente devido aos baixos salários pagos a essa parcela da população e pelas precárias estruturas de transporte e comunicação. Apesar da primeira fase da Revolução Industrial ter sido marcada pela exploração exacerbada da classe trabalhadora, na visão de Krippendorf (2003, p.105):

as conseqüências do advento da sociedade industrial foram o bem-estar material e a eliminação da pobreza. Os progressos foram de duas ordens: aumento dos salários e redução do tempo de trabalho. Esses dois índices de medida do bem-estar tornaram-se uma profissão de fé da sociedade industrial. Os resultados são formidáveis: embora no século XVIII e até o início do século XIX uma grande camada da 
população trabalhasse de 4.000 a 4.500 horas por ano e uma parte, inclusive, 15 horas por dia, 7 dias por semana, o número de horas de trabalho se estabelece, no momento, nos países industrializados, entre 1.700 e 2.100 por ano. O ganho do tempo livre foi, portanto, considerável $[\ldots]$.

Para Krippendorf (2003), mesmo diante de tais avanços, a pobreza não deixou de existir a partir da sociedade industrial, não obstante o surgimento de oportunidades de emprego, uma vez que nessa fase a mão-de-obra não era tão excedente como no período pós-industrial.

Nos séculos XVII e XVIII apenas as classes mais abastadas viajavam por prazer, porém, devido ao puritanismo essas viagens eram intituladas de viagens de saúde e/ou educacionais. A natureza hedonista do lazer/férias só passa a ser admitida em meados do século XIX (CORMACK, 1998).

Com a instituição do tempo livre, as atividades de lazer passam a fazer parte dessa nova sociedade. Todavia, "sair de férias" ainda era, para a massa trabalhadora, algo diferente do que vemos hoje, apesar de a viagem continuar sendo um bem inacessível para muitos. Naquela época, a discrepância entre os que podiam e os que não podiam usufruir das viagens era ainda maior.

É na segunda fase da Revolução Industrial que o turismo ganha forma e força enquanto atividade socioeconômica. Um dos responsáveis por essa nova feição dada ao turismo foi o inglês Thomas Cook, que em 1841, fretou um vagão de um trem e realizou a primeira excursão organizada no mundo. 0 sistema ferroviário era antes utilizado com o único intuito de transportar cargas e a partir de 1840 passou a transportar passageiros e daí por diante não parou mais. O "visionário" Thomas Cook promoveu uma verdadeira revolução no mercado de viagens e turismo, ao introduzir as excursões organizadas, características do turismo de massa em todo o globo, o que atualmente tem sido criticado, especialmente por alguns cientistas sociais críticos sobre tal processo.

O turismo enquanto atividade mercantil toma novo impulso a partir da Segunda Guerra Mundial, quando os meios de comunicação e transportes passam por uma grande evolução. A introdução dos aviões nas viagens de 
lazer marca a nova era do setor de viagens e turismo, beneficiado, mais uma vez, pelos avanços tecnológicos, em especial na área de comunicação e informação.

\section{Sociedade Informacional e Turismo}

Nessa nova fase, do avanço do meio técnico-científico e informacional, a ciência e a tecnologia assumem papel importante na produção socioeconômica, pois segundo Santos (2008a, p.19) "a técnica é a grande banalidade e o grande enigma, e é como enigma que ela comanda nossa vida, nos impõe relações, modela nosso entorno, administra nossas relações com o entorno".

Ainda para Santos (2008a, p. 40):

o meio técnico-científico-informacional é a nova cara do espaço e do tempo. É aí que se instalam as atividades hegemônicas, aquelas que têm relações mais longínquas e participam do comércio internacional, fazendo com que determinados lugares se tornem mundiais.

Entretanto, os avanços do meio técnico-científico-informacional se apresentam de forma bastante desigual e contraditória socioterritorialmente, pois nem todos os lugares e classes sociais usufruem de fato dos benefícios gerados por este meio. Há desigualdade, tanto no uso, quanto na produção e geração das tecnologias, processo este que marca sobremaneira a sociedade informacional.

Para Levitt (1998), a tecnologia é uma poderosa força que impulsiona o mundo para a uniformização. Esta força transformou as comunicações, o transporte e as viagens e fez de locais isolados e de povos empobrecidos entidades ansiosas por usufruírem dos atrativos da modernidade. Na visão de Levitt, a globalização dos mercados seria algo inevitável. Já para Santos (2008a, p. 50), "quanto mais a globalização se aprofunda [...] mais forte é a tensão entre globalidade e localidade, entre o mundo e o lugar [...]". 
Ainda para Santos (2008a), a importância do movimento e relativo desaparecimento das distâncias permitiram a alguns acreditar na homogeneização do espaço. De fato, porém, o espaço torna-se mais diversificado e heterogêneo.

$\mathrm{Na}$ verdade são duas forças contrárias, ao mesmo tempo em que o processo de globalização leva à unificação, surge a necessidade de identificação local e o desejo de diferenciação, gerando muitas vezes resistências e lutas contra o globalitarismo. No caso do turismo esses dois processos ocorrem simultaneamente, pois ao mesmo tempo em que ocorre a padronização dos serviços, as localidades buscam diferenciar-se uma das outras como forma de oferecer um "produto autêntico".

Se, ao longo da história da humanidade, a riqueza esteve sempre ligada à posse e ao controle de recursos materiais, hoje a riqueza não é apenas algo material, palpável, é também imaterial: o conhecimento. O conhecimento é a fonte primária de riqueza na sociedade pós-industrial.

A revolução tecnológica e a transformação social estão ligadas à inserção da informação por toda a estrutura social, daí que o grau de desenvolvimento das sociedades, atualmente no modo de desenvolvimento informacional, tem no número de computadores por habitante um indicador fundamental (CASTELLS, 2000).

Ao transformar e produzir tecnologia em busca de novos conhecimentos e novas formas de processamento das informações, a sociedade acaba inevitavelmente se organizando em forma de rede, sendo esta uma de suas características principais. Na verdade, o que caracteriza a presente revolução tecnológica não é a centralidade do conhecimento e da informação, mas a aplicação de tal conhecimento e informação para gerar conhecimento e dispositivos de processamento de informação e conhecimento (CASTELLS, 2000). Durante toda a história a incipiência da técnica impediu, ou ao menos limitou a proliferação da idéia de organização social em rede e, hoje, frente ao suporte técnico existente, outro padrão social emerge dessas novas relações. 
No caso específico do turismo, tanto as novas tendências tecnológicas como as conseqüências da sociedade em rede são positivas do ponto de vista econômico, sendo necessária e indispensável a preocupação com o desenvolvimento desta área, especialmente, nas nações subdesenvolvidas, onde muitas vezes o turismo não tem gerado impactos sobretudo positivos.

Um dos impactos gerados por esta atividade "globalizada" é o aumento das viagens em decorrência da popularização do turismo de massa. Esta modalidade de turismo vem sendo cada vez mais estimulada pelo empresariado, graças, principalmente, às facilidades tecnológicas e de informação. Isso gera certa contradição à medida em que os estudiosos do turismo vêem no turismo de massa uma ameaça à preservação dos ambientes naturais e sociais apropriados pela atividade turística. Essa massificação tecnológica é contestada por Santos (2008b, p.39), que destaca que

todavia, nas condições atuais, as técnicas da informação são principalmente utilizadas por um punhado de atores em função de seus objetivos particulares. Essas técnicas da informação (por enquanto) são apropriadas por alguns Estados e por algumas empresas, aprofundando assim os processos de criação de desigualdades. É desse modo que a periferia do sistema capitalista acaba se tornando ainda mais periférica, seja porque não dispõe totalmente dos novos meios de produção, seja porque the escapa a possibilidade de controle.

Apesar da popularização da informação, a sociedade informacional é de todo o modo seletiva, pois o seu alcance não atinge todos os lares e cidadãos do mundo. Os avanços tecnológicos não chegam para todos simultaneamente, pois até chegar ao destinatário final, enfrentam barreiras sociais, educacionais e econômicas. É por isso que, para Santos e Silveira (2002, p.93), "devemos entender a informação como um recurso, com áreas de abundância e áreas de carências".

A afirmação de Santos está bem ilustrada na figura 1, que mostra como o mundo se comporta diante da sociedade em rede. Observa-se uma forte concentração de fluxos entre os grandes centros econômicos mundiais. No mapa abaixo estão representadas as 100 maiores multinacionais interligadas 
ISSN: $1982-6125$

num sistema em rede. Essas, por sua vez, representam "os espaços do mandar" que, na visão de Santos e Silveira (2002, p.263),

[...] são ordenadores da produção, do movimento e do pensamento em relação ao território como um todo. Este último, o pensamento, dá-se por meio de todas as modalidades de informação subjacentes à produção moderna. É a partir do nexo informacional que se instala o nexo circulacional, criando-se o movimento, inclusive o do próprio turismo, cujos pólos receptores são mais difusos e podem ser menos poderosos que os pólos emissores. Na mesma ordem de idéias, a produção que dinamiza certas áreas tem seu motor primário ou secundário em outros pontos do território nacional ou mesmo do estrangeiro.

Dessa forma vai se configurando um novo mapa do mundo, evidenciando a sociedade em rede que se circunscreve no período informacional. Redes que se intensificam cada vez mais com os avanços da técnica e da globalização, tornando-se complexas e difícil de serem entendidas, haja vista os diferentes fluxos que as perpassam, isso nos mais diversos âmbitos, político-ideológico, econômico, cultural, etc. Nesse entremeio, aparece também o turismo com sua capacidade de transformar os espaços regionais e os lugares.

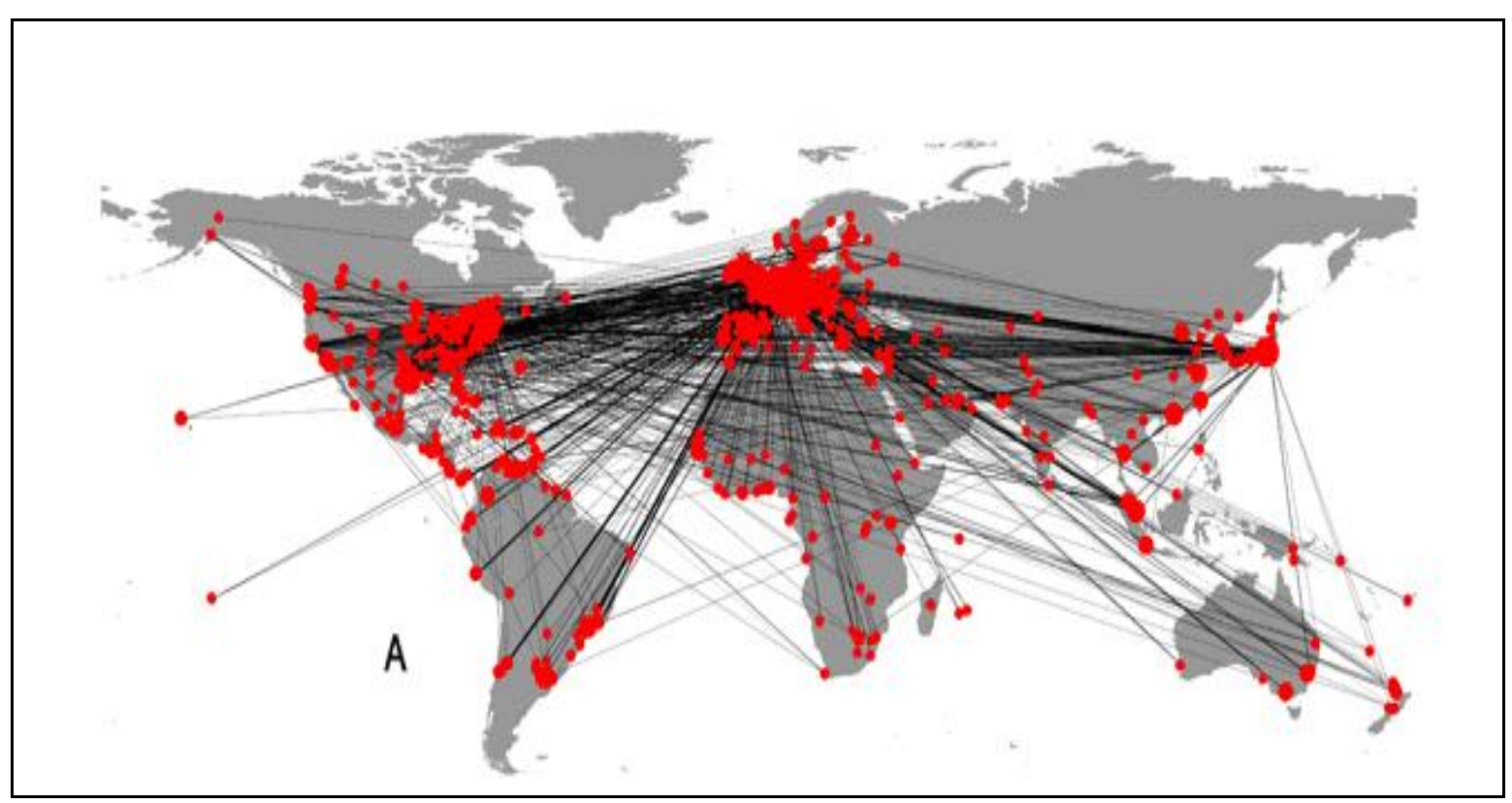

Figura 1: Mapa de Relações das 100 Maiores Multinacionais em Rede

Fonte: WALL (2009). Disponível em: http://www.lboro.ac.uk/gawc/rb/rb294.html\#fig2GIS 
Sabe-se que o turismo é uma atividade que envolve, necessariamente, deslocamento espacial. Portanto, seguindo ainda a linha de pensamento de Milton Santos essa mesma relação entre as multinacionais se dá dentro do mercado e dos fluxos turísticos, pois, como destaca o autor, os pólos receptores acabam por serem dependentes dos pólos emissores. Esse mapa é válido também para ilustrar as principais rotas turísticas, pois conforme Santos e Silveira (2002, p.261 e 262):

[...] a densidade viária e infoviária não tem, pois, relação direta com o tamanho e a densidade da população, nem com a antiguidade do povoamento, nem com as urgências das sociedades locais, mas com os nexos econômicos, sobretudo os da economia internacional.

A sociedade em rede cria necessidades de maior circulação dos homens, dos produtos, das mercadorias, do dinheiro, da informação. Tais necessidades acarretam melhorias nas infraestruturas de transporte e comunicação, bem como na melhoria das superestruturas turísticas ${ }^{3}$. Mais uma vez, os países ricos ou grandes centros econômicos se destacam por terem e estarem mais abertos a essa fluidez.

Torna-se relevante frisar que a intenção não é apontar os pontos negativos dessa atual fase histórica, mas sobretudo levantar os pontos positivos, principalmente, porque um dos temas relacionados nessa análise é a atividade turística que por suas características socioeconômicas passam a depender fortemente da evolução tecnológica. Além disso, cabe destacar que ao longo da história do turismo, a tecnologia foi responsável pelo seu crescimento e impulso econômico. Ou seja, a atividade turística é moldada através dos avanços tecnológicos.

\section{Informação, Turismo e Internet}

${ }^{3}$ Entenda-se por superestrutura os equipamentos turísticos. 
Como conseqüência da revolução tecnológica, a informação passa a ser um produto de influência significativa nas economias mundiais, regionais e locais. As empresas tendem a se adaptarem às novas exigências do mercado e a se adequarem aos avanços tecnológicos a fim de se manterem competitivas e garantirem sua sobrevivência no mercado.

A crescente demanda turística vem impulsionando a ampliação das fontes de informação às quais o potencial turista possa vir a ter acesso. Neste contexto, torna-se cada vez mais urgente o uso das novas fontes de informação como veículo difusor dos serviços e informações turísticas. A Internet é um exemplo de fonte alternativa de informação, haja vista que tal fonte surge e se consagra como uma poderosa ferramenta de comunicação e distribuição, cada vez mais presente no dia a dia da sociedade. Seja apenas como uma forma de lazer, cultura, informação ou como uma ramificação do trabalho, a Internet torna-se quase que indispensável na atualidade. Portanto, não é estranho que um número cada vez maior de empresas e destinos turísticos esteja se voltando para a $W e b$, devido aos benefícios oferecidos por este meio de informação e comunicação.

Para Cooper (2001), as tecnologias da informação e comunicação são sistemas de hardware, software e humanware, tais como telex, telefones, fax, computadores, sistemas de gerenciamento de informações, teleconferências, multimídias, intranet, Internet, satélite, entre outros. Entretanto, a Internet foi o avanço tecnológico que mais facilitou a interatividade das organizações e dos indivíduos com o mundo exterior.

Quevedo (2007, p.22-23) faz um relato histórico da automação dos serviços na indústria turística:

nos anos de 1970, a atividade turística sofreu mudanças estruturais. A implementação de redes de computadores e sistemas eletrônicos de distribuição da informação permitiram que as empresas gerenciassem melhor seus produtos e serviços. Na década de 1980, as companhias aéreas passaram a utilizar um sistema de reserva por computador, conectados aos grandes agentes, o que possibilitou dominar novos mercados. Porém, as evoluções nos sistemas de distribuição globais, 
foram efetivadas a partir da expansão da Internet e da WWW - World Wide $W e b$, em meados dos anos de 1990.

A utilização dos sistemas de reservas computadorizados agilizou os processos das companhias aéreas, proporcionando maior comodidade a seus clientes, resultando muitas vezes em maior capacidade de lucro, todavia significando, as vezes, dispensa de recursos humanos. As reservas on-line, a emissão eletrônica de passagens, as ofertas eletrônicas de última hora e o check in pela Internet ou celular são alguns exemplos. E como conseqüência do uso das TIC's (Tecnologias da Informação e Comunicação), houve uma ampliação do mercado das empresas aéreas, maior facilidade no gerenciamento da rentabilidade destas, além de barateamento dos seus serviços para o consumidor final.

Quase tudo contribui para o aumento do fluxo de viagens que, por sua vez, ocorre com mais freqüência, em especial, devido às necessidades do ser humano em se distanciar da rotina diária, bem como das facilidades de transporte, de comunicação e de informação que hoje são encontradas. O avanço e o uso da tecnologia vêm transformando consideravelmente o setor de turismo, especialmente os canais de distribuição do produto turístico, embora isso também ocorra de forma desigual e difuso socioterritorialmente.

As transformações estabelecidas a partir da introdução das tecnologias da informação foram bastante significativas, pois impactaram a distribuição do produto turístico de duas formas: de um lado, criando um canal direto com o consumidor final; de outro com o uso da Internet criou-se um canal de distribuição direto com o consumidor, com custos mais acessíveis, diminuindo a subjetividade na transmissão das informações, não obstante as tranformações ocorridas no mundo do trabalho.

Para Bissoli (1999, p.55), "o setor de turismo estará cada vez mais vinculado a tecnologias que permitem melhorar a prestação de serviços, reduzir custos, incrementar a produtividade e melhorar a qualidade do atendimento." Ainda para a autora, a tecnologia é um caminho sem volta, pois a informatização da sociedade é um processo irreversível. 
A informação é, para a revolução informacional, o que as fontes de energia foram para a revolução industrial. As tecnologias da informação não são ferramentas simples de aplicação, mas processos para serem desenvolvidos e aperfeiçoados contínua e progressivamente. Na verdade, o usuário pode ter o controle da tecnologia, como por exemplo, na Internet, mas sempre submetido a obsolescência programada, isto é, a capacidade que a tecnologia (e os objetos) têm de se tornar obsoleta em determinados intervalos de tempo.

Nesse contexto, as novas tecnologias têm uma relação próxima com o processo social de criação e manipulação de símbolos e a capacidade de produzir e distribuir bens e serviços. Pela primeira vez na história, a mente humana é força de produção direta, não apenas um elemento de decisão do sistema de produção. (CASTELLS, 2000).

No caso do turismo, a informação deve ser a mais pulverizada possível para que melhore seu desempenho. A informação é o principal instrumento e ferramenta de trabalho de um profissional da área. Sem informação não existe turismo, pois o ator principal desse processo, o turista, não reside no local a ser visitado. Fato que torna imprescindível o acesso a informações precisas e confiáveis acerca do local a ser visitado.

Segundo Buhalis (2008, p.610-611):

os turistas das mais variadas regiões do mundo são hoje viajantes freqüentes, eles dominam as novas tecnologias e falam outros idiomas [...]. O desenvolvimento das TIC e, em particular, a Internet dão poder aos "novos" turistas que cada vez mais vem procurando por preços baixos e economia de tempo. Eles estão menos interessados em seguir as multidões em pacotes turísticos de massa, pois querem planejar suas viagens do início ao fim. (tradução livre)

Diante disso a informação adquire papel importante na atividade turística, pois de acordo com Buhalis (2008), um turista bem informado interage melhor com os recursos e cultura locais, a fim de encontrar produtos e serviços que atendam aos seus interesses. 
A Internet, através de web sites turísticos deixa de ser uma mera fonte de informação e passa a agir como fonte de influência direta na imagem do destino, à medida que oferece aos seus consumidores rico conteúdo de informação e opções interativas com a página da web. À medida que o usuário ver nesse veículo de informação a possibilidade de interação, aumentará sua chance de retornar ao site para a busca de informações adicionais. Além disso, os web sites podem capturar informações sobre as preferências dos clientes, e usar essas informações para fornecer serviços e comunicação personalizadas. (DOOLIN et al., 2002). Essa utilização dos dados dos clientes caracteriza um novo paradigma que se denomina marketing direto, marketing pessoa a pessoa e database marketing (comunicação de marketing endereçada de forma personalizada) que é possível graças ao advento da Internet.

\section{Considerações Finais}

A sociedade atual é marcada por um ilimitado, mas também desigual acesso à informação, pelo crescente aumento do tempo livre, ao menos para as sociedades mais desenvolvidas, e pela busca por uma melhor qualidade de vida. Dentre as inúmeras conseqüências da revolução tecnológica, destaca-se o retorno da casa como ambiente de trabalho, the home Office is back.

Essa realidade já existiu no período anterior à revolução industrial, onde as relações de trabalho caracterizavam-se pela produção manual e pela não separação entre casa e trabalho. A separação entre local de trabalho e residência foi um dos marcos da revolução mencionada. A principal diferença entre esses dois períodos reside na qualificação do ofício: hoje a casa é local do trabalho intelectual. Torna-se relevante informar que a dinâmica dessa sociedade afeta diretamente a atividade turística, que ganha destaque como uma das mais importantes atividades socioeconômicas do presente século.

A conseqüência dessa nova estrutura social gera na atividade turística uma posição de destaque, pois a automação dos serviços turísticos cria nova 
relação entre consumidores e empresas (turistas e turismo). Com a diminuição considerável dos agentes intermediários, ocorre uma expressiva redução dos serviços turísticos e uma maior sensação de independência do "novo turista", que passa a planejar mais e melhor suas viagens. A maior facilidade do acesso à informação vem tornando o turista mais exigente e as empresas mais qualificadas, transformando-se em estruturas de conhecimento, que buscam novos serviços, produtos e mercados.

Por fim, todo o aparato tecnológico gira a favor da expansão, ou melhor, massificação das viagens, o que é positivo do ponto de vista econômico, no entanto não tão positivo assim do ponto de vista socioambiental e até mesmo cultural, quando muitas vezes áreas são apropriadas e totalmente transformadas pelo turismo.

Mas, não se pode desconsiderar os novos processos em curso, haja vista a constituição de uma nova "era turística", onde o meio técnico-informacional, característico do período atual, na sociedade da informação, vem evidenciando turistas mais conscientes e mais bem informados, assim como exigentes em relação aos princípios éticos socioambientais. É o conhecimento que marca essa atual sociedade, sendo este fator estratégico para essa nova economia baseada na informação, basta que se saiba tirar o devido proveito em prol do desenvolvimento econômico e social a partir do turismo.

\section{Referências}

BISSOLI, Maria A. M. A.. Planejamento turístico municipal com suporte em sistemas de informação. São Paulo: Futura, 1999.

BLANKE, Jennifer; CHIESA, Thea. Travel and tourism competitiveness report 2009. Geneva, Switzerland: World Economic Forum. Disponível em: $<$ http://www.weforum.org/en/initiatives/gcp/TravelandTourismReport/index.ht m>. Acesso em: mai. 2009.

BUHALIS, Dimitrios; LAW, Rob. Progress in information technology and tourism management: 20 years on and 10 years after the Internet-The state of eTourism research. Tourism Management. p.609-623. Science Direct, 2008. CASTELLS, M.. The rise of the network society. The information age: economy, society and culture. 2.ed. Oxford: Blackwell, v.1., 2000. 
COOPER, C. et al. Turismo; princípios e prática. Tradução R. Costa. Porto Alegre: Bookman, 2001.

CORMACK, Bill. The history of tourism, 1812 - 1990: Thomas CooK and the origins of leisure and travel. London: Routledge, 1998.

DOOLIN, B.; BURGESS, L.; COOPER, J.. Evaluating the use of the web for tourism marketing: a case study from New Zealand. Tourism Management, Vol. 23, No.5, pp.557-561, 2002.

KRIPPENDORF, Jost. Sociologia do Turismo: para uma nova compreensão do lazer e das viagens. 3.ed. São Paulo: Aleph, 2003.

LEVITT, Theodore. A Globalização dos mercados. In: MONTGOMERY, A. Cynthia; PORTER, Michael E. (org.). Estratégia: a busca da vantagem competitiva. São Paulo: Campus, 1998, p.197-215.

OMT. Turismo Internacional: uma perspectiva global. 2.ed. Porto Alegre: Bookmann, 2003.

O'CONNOR, Peter. Distribuição da informação eletrônica em turismo e hotelaria. Porto Alegre: Bookman, 2001.

PEASE, Wayne; ROWE, Michele; COOPER, Malcolm. Information and communication technologies in support of the tourism industry. USA, Hershey: Idea Group Publishing, 2007.

QUEVEDO, Mariana. Os impactos das tecnologias de informação e comunicação no turismo. In: QUEVEDO, Mariana (org.). Turismo na era do conhecimento. Florianópolis: Pandion, 2007.

SANTOS, Milton. Técnica, espaço, tempo: globalização e meio técnicocientífico-informacional. 5.ed. São Paulo: Edusp, 2008a.

SANTOS, Milton. Por uma outra globalização: do pensamento único à consciência universal. 17.ed. Rio de Janeiro: Record, 2008b.

SANTOS, Milton; SILVEIRA, Maria Laura. O Brasil: território e sociedade no início do século XXI. 4.ed. Rio de Janeiro: Record, 2002.

WALL, R.S.. The relative importance of Randstad Cities within comparative worldwide corporate networks. Disponível em: <http://www.lboro.ac.uk/gawc/rb/rb294.html\#fig2GIS> Acesso em: ago.2009.

Artigo recebido em março de 2010.

Aprovado para publicação em agosto de 2010. 